\title{
Evaluating the Cariogenic Potential of Flavored Milk: An Experimental Study using Rat Model
}

\author{
${ }^{1}$ Asma Al-Jobair, ${ }^{2}$ Rita Khounganian
}

\section{ABSTRACT}

Objective: The purpose of this study was to evaluate and to compare the cariogenic potential of different commonly consumed flavored milk on caries development in rat's molar teeth.

Materials and methods: Sixty Sprague-Dawley rats infected with an active growing culture of Streptococcus mutans were offered chocolate flavored milk, strawberry flavored milk, banana flavored milk, plain milk, sweetened plain milk with $5 \%$ sucrose, and $10 \%$ sucrose ad libitum.

Results: Rats consuming flavored milk developed significantly lower sulcal and smooth surface caries scores than rats consuming $10 \%$ sucrose. However, rats consuming plain milk developed significantly lower sulcal and smooth surface caries scores than animals consuming flavored or sweetened plain milk except for chocolate flavored milk.

Conclusion: It was concluded that flavored milk containing 5\% sucrose showed a moderate cariogenic potential.

Clinical significance: Although the overall results suggest that the cariogenic potential of flavored milk is moderate and despite their nutritional value, occasional consumption of flavored milk as a beverage might be accepted with caution. Parents, dental practitioners and other healthcare professionals should be aware of the cariogenicity of flavored milk. They should keenly encourage the use of plain milk and discourage the use of any cariogenic drink which has a deleterious effect on teeth.

Keywords: Flavored milk, Dental caries, Rats, Streptococcus mutans.

How to cite this article: Al-Jobair A, Khounganian R. Evaluating the Cariogenic Potential of Flavored Milk: An Experimental Study using Rat Model. J Contemp Dent Pract 2015;16(1):42-47.

Source of support: College of Dentistry Research Center, King Saud University.

\section{Conflict of interest: None}

${ }^{1}$ Department of Pediatric Dentistry and Orthodontics College of Dentistry, King Saud University, Riyadh, Saudi Arabia

${ }^{2}$ Department of Oral Medicine and Diagnostic Sciences College of Dentistry, King Saud University, Riyadh, Saudi Arabia

Corresponding Author: Asma Al-Jobair, Associate Professor, Department of Pediatric Dentistry and Orthodontics, College of Dentistry, King Saud University PO Box 60169, Riyadh 11545, Saudi Arabia, Phone: 966114676648, e-mail: aaljobair@ksu.edu.sa

\section{INTRODUCTION}

Milk is of a major nutritional value, especially for children and adolescents. Flavors that appeal to children, such as vanilla, strawberry, chocolate, and banana have been introduced and became more popular in recent years. ${ }^{1}$ Flavored milk is a nutrient rich beverage that provides essential nutrients similar to unflavored milk except for the added sugar, which adds about 60 to 70 calories per 8 -ounce serving. ${ }^{2}$ It provides an option for meeting the recommended intakes of dairy products. According to the data from the US Department of Agriculture and the US Department of Health and Human Services, ${ }^{3} 70 \%$ of the milk chosen by children in schools is flavored. Kranz et al ${ }^{4}$ showed that $18 \%$ of 4 to 18 -year-old children's dairy consumption is flavored milk suggesting its popularity among school children. In Saudi Arabia, more than $50 \%$ of adolescents consume chocolate flavored milk compared to $25 \%$ who consume plain milk. ${ }^{5}$ Pelsmaeker et $\mathrm{al}^{6}$ showed that children prefer flavored milk to plain milk, although it is perceived to be less healthy. Children at this stage are in a calcium crisis as most of them are not meeting current calcium recommendations. ${ }^{7}$ Johnson et al ${ }^{8}$ showed that children who drink flavored milk consume more milk and hence have higher calcium intake. The American Academy of Pediatric ${ }^{9}$ has recognized the value of flavored milk with modest amount of sugar for school children. They recommended the consumption of low fat or fat-free plain or flavored milk as a healthful alternative to soft drinks. When flavored milk was taken out of schools, the overall milk consumption dropped by approximately $38 \%{ }^{8}$

Food flavors can be classified into natural flavors which come from animal and vegetable sources, nature identical flavors which are chemically identical to natural flavorings but are prepared or extracted using chemical methods, and artificial flavors, compounds which are not chemically identical to natural flavoring substances and have not been identified in nature. ${ }^{10}$ According to the Code of Federal Regulations, flavors other than natural flavors, are considered artificial. ${ }^{11}$ Most of the flavors used in food industry are artificial. The impact of contemporary changes in beverage consumption particularly flavored milk, and the presence of these flavors, artificial colors, and added sugar raises some 
questions about their potential effects on children's general health. ${ }^{12,13}$ In addition, the issue about their cariogenicity has also been raised. ${ }^{14}$ Miller et $\mathrm{l}^{15}$ showed that the top sources of added sugars among Americans aged 2 to 11 years were soda, fruit drinks, and flavored milk. Flavored milk typically contains $5 \%$ or more of added sugar in addition to 4 to $5 \%$ of lactose. ${ }^{16}$

Dental caries is one of the most prevalent infectious diseases to afflict mankind. ${ }^{17}$ Streptococcus mutans is most commonly associated with carious lesions in humans ${ }^{18,19}$ as well as in experimental animals on sucrose diets. ${ }^{20}$ S. mutans metabolizes carbohydrates, such as glucose, lactose and sucrose, to produce acid and induce dental caries. ${ }^{21,22}$ Many types of food promote the development of dental caries and are therefore known as cariogenic. However, some types of food, like milk and milk products contain factors believed to protect against dental caries and are therefore supposed to be anticariogenic or cariostatic. ${ }^{23}$ Adding sugar to milk could risk its cariostatic effect. A study on rats showed an increase in cariogenicity with only $2 \%$ sucrose added to milk. ${ }^{24}$ Furthermore, Bowen et $\mathrm{al}^{25}$ reported that $5 \%$ sucrose is highly cariogenic.

Although the cariogenic effects of sweetened milk, human milk and infant formula have been studied, ${ }^{24,26-28}$ the interaction between different kinds of flavored milk and caries development should be better understood and investigated. Therefore, the present investigation was carried out to evaluate and to compare the cariogenic potential of commonly consumed flavored milk on caries development in rat's molar teeth.

\section{MATERIALS AND METHODS}

Sprague-Dawley pregnant rat dams were obtained from the Centre of Laboratory Animals and Experimental Surgery (CLAES), at King Khalid University Hospital, King Saud University (KSU) in Riyadh and transferred to the animal house of the College of Dentistry, (KSU). The animals were fed with chow diet (F-648; Grain Silos \& Flour Mills Organization, Riyadh Branch, Saudi Arabia) and distilled water ad libitum. They were maintained under standard conditions of humidity $(50-55 \%)$, temperature $\left(23-25^{\circ} \mathrm{C}\right)$, and light (12 hours light/12 dark cycles). All procedures were performed in accordance with the Guide for the Care and Use of Laboratory Animals, after the approval of the Ethical Committee at the College of Dentistry Research Centre (CDRC), (KSU). Only pups born within a 24-hour period were used and the dams were circulated among the litters. ${ }^{29}$ Pups were weaned when aged 21 days. ${ }^{26}$

Freeze dried pure culture of S. mutans (ATCC 25175) available in the microbiology laboratory of the College of Dentistry, $\mathrm{KSU}$ and stored at $-20^{\circ} \mathrm{C}$ was cultured in Todd-Hewitt broth media (BBL Microbiology Systems, Cockeysville, MD, USA) and was incubated at $37^{\circ} \mathrm{C}$ for 24 hour. ${ }^{30}$ Each pup was then infected for three consecutive days (21st-23th days of age) by oral inoculation of 3 drops of the bacterial suspension using a pipette. ${ }^{30}$ The pups were restrained from any fluid or food for at least 1 hour following the infection. During this period, the pups were given laboratory chow containing $25 \%$ sucrose. $^{31}$ In addition, a freshly cultured bacterial suspension was diluted 1/100 and was added to their drinking water, ${ }^{30}$ with $10 \%$ sucrose to enhance establishment of infection. ${ }^{26}$

Forty-eight hours after inoculation was completed, several oral swabs were taken from selected animals and were cultured. ${ }^{30}$ Oral swaps were placed in $10 \mathrm{ml}$ tube of Todd-Hewitt broth media and were incubated for 24 hours. Then $10 \mu \mathrm{l}$ was taken and spread on blood agar plate (Oxoid LTD, Basingstoke, Hampshire, UK) and was incubated for 24 hours. After that, the plate was checked for alpha hemolytic organisms then was checked by MicroScan machine (Siemens Healthcare Diagnostic Inc., $\mathrm{Ca}$, USA) to determine the presence or absence of the organism. It revealed that all selected animals were successfully infected by $S$. mutans.

Rats were then randomly divided into 6 groups comprising 10 animals each. All animals were weighed to monitor their growth rates. The animals were maintained under standard laboratory conditions and subjected to the same 12 hours light/dark cycle and the same times of feeding, handling and noise level during the experimental period.

The animals were housed in pairs, in cages with raised wire stainless steel floors with all-time access to distilled water and to a commercial non cariogenic laboratory powdered pellet chow diet ad libitum; containing $20 \%$ protein, $4 \%$ fat, $3.5 \%$ fibre, $6 \%$ ash, $0.5 \%$ salt, $1 \%$ calcium, $0.6 \%$ phosphorus as well as vitamin A, D and E. Trace minerals, such as cobalt, copper, iodine, iron, manganese, selenium and zinc were also included (F-648; Grain Silos \& Flour Mills Organization, Riyadh Branch, Saudi Arabia).

Each group was accordingly offered one of the following fluids to drink ad libitum; 1) banana flavored milk; 2) chocolate flavored milk; 3) strawberry flavored milk; 4) sweetened plain milk with 5\% sucrose; 5) plain milk (negative control); and 6) 10\% sucrose (positive control). Long life plain and flavored milk (2-3\% fat) were purchased in a local supermarket and replenished daily in sterile bottles to reduce risk of spoilage. The rats were regularly examined and weekly weighed and the amount of consumed fluids under investigation was monitored and weekly recorded. By the end of the 5th week, the rats were sacrificed using ether; the mandible and maxilla were removed and defleshed. 
All molars on each side of the jaws were scored for number and severity of smooth surface (buccal/ lingual) and sulcal surface caries by a trained examiner who was unaware of the groups, by means of Nikon stereomicroscope (SMZ 1000) (Nikon Instruments Inc, NY, USA) with magnification of $40 \times$ using modified Keyes method. ${ }^{32}$ Considering unsliced and unstained tooth surfaces: 'enamel lesions' were scored when the caries progression was restricted to the enamel, whereas 'dentinal lesions'were scored when signs of caries penetration were seen at least in the dentino-enamel junction or further into the dentin. Enamel and dentinal caries were assessed for each molar surface in each rat separately then they were added together giving the total caries score for the smooth surfaces (buccal/lingual) and sulcal surfaces independently.

Total sugar analysis of all tested drinks was performed using high performance liquid chromatographs (HPLC) (Shimadzu, Japan) and the concentration of various sugars was expressed as a percentage. The $\mathrm{pH}$ of the consumed fluids was also measured with a $\mathrm{pH}$ meter at room temperature.

The data were analyzed using the statistical package for social sciences (SPSS version 16) program. The caries data were calculated as mean \pm standard deviation. Statistically significant differences among the groups were determined by analyses of variance (ANOVA) and Tukey's test with a statistical significance level of 0.05 .

\section{RESULTS}

The experiment continued for five weeks and all animals survived the experimental procedures and remained in apparent good health.

Table 1: Total sugar and $\mathrm{pH}$ level of consumed fluids

\begin{tabular}{lllll}
\hline Consumed fluids & $\begin{array}{l}\text { Sucrose } \\
(\%)\end{array}$ & $\begin{array}{l}\text { Lactose } \\
(\%)\end{array}$ & $\begin{array}{l}\text { Total sugar } \\
(\%)\end{array}$ & $\mathrm{pH}$ \\
\hline Plain milk & 0.00 & 4.67 & 4.67 & 6.5 \\
Chocolate milk & 5.90 & 4.76 & 10.66 & 6.3 \\
Strawberry milk & 5.15 & 4.42 & 9.57 & 6.3 \\
Banana milk & 5.50 & 5.01 & 10.51 & 6.2 \\
Plain milk + 5\% sucrose & 5.00 & 4.73 & 9.73 & 6.0 \\
Sucrose & 10.00 & - & 10.00 & 5.7 \\
\hline
\end{tabular}

The relative determinations of total sugar levels as well as the $\mathrm{pH}$ of the consumed fluids are indicated in Table 1. The total sugar concentration of the chocolate flavored milk was the highest $(10.66 \%)$ and the plain milk was the lowest $(4.67 \%)$ which demonstrated the highest $\mathrm{pH}$ value (6.5). The highest consumption was among strawberry flavored milk group (Table 2). Flavored milk drinks were consumed more than other milk.

Rats consuming flavored milk developed significantly lower sulcal and smooth surface caries scores than rats consuming $10 \%$ sucrose $(\mathrm{p}<0.05)$ (Table 2$)$. On the contrary, rats consuming flavored and sweetened plain milk had significantly higher caries scores when compared to the caries scores of rats consuming plain milk $(p<0.05)($ Table 2). However, for the total sulcal surface caries scores, no significant difference was detected between chocolate flavored milk and plain milk. Although sweetened plain milk group had higher smooth and sulcal caries scores than other flavored milk groups, significant differences were not detected among them (Table 2).

\section{DISCUSSION}

Murphy et $\mathrm{al}^{33}$ emphasized that the effect of added sugar on body mass index (BMI) did not differ between flavored milk drinkers and milk non-drinkers, however, the effects of these sugars on dental health have not been taken into consideration.

The caries process is multifactorial and involves integration of several factors, such as oral bacteria, saliva, tooth enamel, and dietary substrates. It is possible to learn a great deal about each of these factors by studying them individually or in limited combinations. ${ }^{16}$ The rat caries model incorporates many aspects of the caries process in vivo and is, therefore, considered to be a valuable and suitable model to shed some light on the cariogenic potential of frequently consumed different flavored milk in rat's molar teeth.

In this experiment, rats consumed flavored milk more than plain milk or sweetened plain milk. Presumably, the smell, the color or the taste of flavored milk made it more attractive than plain or sweetened plain milk. ${ }^{34}$

Table 2: Approximate amount of fluid consumed by rats in each group at the end of the experiment and the effect of drinking fluids on caries scores in rats ( $n=10 /$ group)

\begin{tabular}{|c|c|c|c|c|c|c|}
\hline & $\begin{array}{l}10 \% \text { Sucrose } \\
\text { mean (SD) }\end{array}$ & $\begin{array}{l}\text { Plain milk +5\% } \\
\text { sucrose } \\
\text { mean }(S D)\end{array}$ & $\begin{array}{l}\text { Banana } \\
\text { milk } \\
\text { mean (SD) }\end{array}$ & $\begin{array}{l}\text { Strawberry } \\
\text { milk } \\
\text { mean }(S D)\end{array}$ & $\begin{array}{l}\text { Chocolate } \\
\text { milk } \\
\text { mean (SD) }\end{array}$ & $\begin{array}{l}\text { Plain milk } \\
\text { mean (SD) }\end{array}$ \\
\hline Amount (ml) & $155(11.2)^{a}$ & $157(7.9)^{a}$ & $192(3.7)^{b}$ & $208(14.1)^{b}$ & $186(6.8)^{b}$ & $155(17.7)^{a}$ \\
\hline $\begin{array}{l}\text { Total smooth surface } \\
\text { lesions }\end{array}$ & $30.3(12.2)^{a}$ & $22.8(5.2)^{\mathrm{b}}$ & $20.3(7.3)^{\mathrm{b}}$ & $19.7(6.7)^{\mathrm{b}}$ & $18.9(4.6)^{\mathrm{b}}$ & $6.3(3.5)^{\mathrm{c}}$ \\
\hline Total sulcal lesions & $35.7(12.1)^{a}$ & $28.7(6.1)^{\mathrm{b}}$ & $23.4(7.7)^{\mathrm{b}}$ & $22.5(10.0)^{\mathrm{b}}$ & $21.7(5.4)^{\mathrm{b}, \mathrm{c}}$ & $12.7(4.2)^{\mathrm{c}}$ \\
\hline
\end{tabular}

Different letters in the horizontal rows indicate significant differences $(p<0.05)$; SD: standard deviation 
In experimental animals, Martínez et $\mathrm{al}^{35}$ showed that rats who were exposed to water sweetened with glucose increased the sweetened water intake gradually; however, no evidence has been provided of whether flavor or sweeteners determined this preference. In humans, Pelsmaeker et $\mathrm{al}^{6}$ found that children find plain milk healthier than flavored milk. However, they clearly preferred flavored milk when judging the taste.

In the present study, although the rats were intact (not desalivated), ${ }^{29,36}$ caries have been developed in all groups which might be due to the cariogenic challenge that had been introduced to all animals at the beginning of the experiment. ${ }^{26}$ The laboratory chow fed to the rats was non-cariogenic and fluoride free, thus any caries developed might be ascribed to the drinks the rats were consuming. All tested fluids produced caries, to varying degrees regardless of the amount being consumed which indicates that the amount of fluids consumed was not directly related to caries development.

Rats consuming 10\% sucrose had higher caries scores than all the other groups, while plain milk group had the lowest. Similar observations were reported by many investigators in which sucrose was by far the most cariogenic and plain milk was the least cariogenic of all their examined products. ${ }^{25,26,29}$ In addition to the sugar concentration, fluid acidity is a very important factor in caries initiation as 10\% sucrose was the most acidic fluid, while plain milk was the least among the tested fluids.

Significant differences in caries scores were found among the groups receiving flavored milk, sweetened plain milk and plain milk. This result contradicts the result of Bowen and Pearson ${ }^{24}$ who found that $2 \%$ milk containing as much as $10 \%$ added sugar was no more cariogenic than $2 \%$ milk without sugar. On the other hand, significant differences in caries scores were observed among the groups receiving flavored milk, sweetened plain milk and $10 \%$ sucrose, although they had the same total sugar concentration $(10 \%)$. This observation suggests that milk is exerting some protection against the cariogenic challenge of sucrose included in the milk as reported by Bowen and Pearson. ${ }^{24}$ Nevertheless, milk containing sucrose is more cariogenic than milk alone. However, when the concentration of sucrose in milk is increased, the $\mathrm{pH}$ level is decreased, which suggest that milk might lose its cariostatic properties.

Milk's apparent low level of cariogenicity could be due to its high buffering capacity and to the presence of other components, including high calcium and phosphate contents. In addition, plaque $\mathrm{pH}$ studies have shown that milk causes only a negligible decrease in plaque $\mathrm{pH} .{ }^{37} \mathrm{Milk}$, including flavored milk also contains components that may be protective against dental caries. ${ }^{38,39}$ Bowen et $\mathrm{al}^{25}$ reported that $2 \%$ milk with $10 \%$ added sugar was less cariogenic than water with $10 \%$ sucrose which indicates that some components in milk may be protective. The plain milk and the flavored milk which have been tested in the present experiment contain approximately 2 to $3 \%$ fat, which aids oral clearance, and adsorbs to the enamel surface and may have a protective role. ${ }^{14}$ Casein, the milk protein has been shown to adsorb to the enamel surface, protecting against demineralization. ${ }^{40}$

In the present study, plain milk sweetened with $5 \%$ sugar group had more caries score than flavored milk groups without significant difference among them although had the same total sugar concentration. This could be related to the nature of the flavors which might have some effects against caries development. Food flavors are mainly esters which might react with sugar or milk components and elevate the $\mathrm{pH}$ and hence reduce the caries scores. This explanation needs further investigation as all flavored milk tested in this experiment contain natural-identical flavors.

Among the flavored milk groups being tested in this study, chocolate flavored milk group had the least caries score, although it had the highest sugar level. This is in agreement with the result of Navia and Lopez ${ }^{29}$ who found that rat fed with chocolate milk gave the lowest caries scores of the other products evaluated. Chocolate is suspected to contain some caries free inhibitory substances. Some investigators reported that the addition of cocoa extracted powder to cariogenic food could be useful in controlling dental caries. ${ }^{41-43}$ Chocolate flavored milk tested in this experiment contains cocoa power in addition to chocolate flavor. In the only relevant clinical trial, institutionalized young people received a daily supplement of $0.45 \mathrm{~L}$ of chocolate milk (5\% sucrose) for 2 years, producing a small but non-significant increase in caries compared with a plain milk supplement. ${ }^{44}$ Numerous nutrition and health organizations agreed that chocolate milk is a healthier alternative to soft drinks and a vital part for meeting the dietary needs of youngsters. ${ }^{45-47}$

However, milk containing $5 \%$ of added sugars is likely to be much less than that of carbonated soft and fruit flavored drinks. Flavored milk is packed with nutrients that make it nutritionally superior to soft drinks and fruit drinks. Children who drink flavored milk have higher total milk intake and consume fewer soft drinks than children who do not drink flavored milk. ${ }^{8}$ Such a result may indirectly and positively affect the teeth through increased level of calcium and milk casein from flavored milk and decreased sugar intake through decreased consumption of soft drinks. 
The results of this study should be carefully compared to others findings due to the differences in protocols, diet, handling procedures, strain of bacteria, caging, weaning age, desalivation, and scoring system. However, within the limitations of this animal study, it can be anticipated that the increase of sucrose concentration in milk affects its cariostatic properties. Further animal studies to investigate the effect of flavors on caries development should be studied separately.

\section{CONCLUSION}

Lounging between $10 \%$ sucrose and plain milk, it can be concluded that the cariogenic potential of flavored milk containing $5 \%$ sucrose is moderate. However, an attempt should be made by the dairy manufacturers to decrease the sugar content in flavored milk as the milk naturally contains 5\% lactose. Flavored milk should not replace the plain milk and if it is consumed as a beverage, their occasional consumption might be accepted.

\section{ACKNOWLEDGMENT}

This research is supported by the CDRC, KSU as funded research \#1161. The authors appreciate the assistance of Mr Michael Giwa, the animal house technician and Mr Hakeem, the microbiology technician.

\section{REFERENCES}

1. Goff HD, Griffiths MW. Major advances in fresh milk and milk products: fluid milk products and frozen desserts. J Dairy Sci 2006;89:1163-1173.

2. Tipton C, Kozak J. International Dairy Foods Association, 2009.

3. U.S. Department of Agriculture and U.S. Department of Health and Human Services: Dietary Guidelines for Americans. 7th Edition, Washington, DC: U.S. Government Printing Office, December 2010.

4. Kranz S, Lin P, Wagstaff D. Children's Dairy Intakein the United States: Too Little, Too Fat? J Pediatrics 2007;151:642-646.

5. Al-Jobair A, Al-Mohaimede A, Al-Shamrany A, Al-Mohareb S. Commonly consumed sugared drinks among Saudi adolescents aged 13-15 years in Riyadh city. Egypt Dent J 2009;55:2543-2553.

6. Pelsmaeker S, Schouteten J, Gellynck X. The consumption of flavored milk among a children population. The influence of beliefs and the association of brands with emotions. Appetite 2013;71:279-286.

7. Atkinson SA,McCabe Gp,Weaver CM,Abrams SA,O'Brien OK. Are current calcium recommendations for adolescents higher than needed to achieve optimal peak bone mass? The Controversy. J Nutr 2008;138:1182-1186.

8. Johnson RK, Frary C, Wang MQ. The nutritional consequences of flavoured-milk consumption by school-aged children and adolescents in the United States. J Am Diet Assoc 2002;102:853-856.

9. American Academy of Pediatrics. Optimizing bone health and calcium intakes of infants, children, and adolescents. Pediatrics 2006;117:578-585.
10. Understanding Food Additives. Flavoring in food. 2008 http://www.understandingfoodadditives.org/pages/Ch2p32.htm.Accessed in April 1, 2014.

11. Code of Federal Regulations (annual edition). Section 172.510 - Natural flavoring substances and natural substances used in conjunction with flavors. 2012.http://www.gpo.gov/ fdsys/pkg/CFR-2012-title21-vol3/pdf/CFR-2012-title21-vol3part172-subpartF.pdf. Accessed in April 4, 2014.

12. Bleich S, Wang YC, Wang Y, Gortmaker S. Increasing consumption of sugar-sweetened beverages among US adults: 1988-1994 to 1999-2004. Am J Clin Nutr 2009;89:372-381.

13. McCann D,Barrett A, Cooper A, Crumpler D, Dalen L, Grimshaw Ket al. Food additives and hyperactive behaviour in 3-year-old and 8/9-year-old children in the community: a randomised, double-blinded, placebo-controlled trial. Lancet 2007;370:1560-1567.

14. Levine RS. Milk, flavored milk products and caries. Br Dent J 2001;191:20.

15. Miller PE, McKinnon RA, Krebs-Smith SM, Subar AF, Chriqui, J, Kahle L, Reedy J. Sugar-sweetened beverage consumption in the U.S. novel assessment methodology. Am J Prev Med 2013;45:416-421.

16. Mundorff SA, FeatherstoneJD,Bibby BG, Curzon ME, Eisenberg AD , Espeland MA: Cariogenic potential of foods. 1. Caries in the rat model. Caries Res 1990;24:334-355.

17. Hicks J, Garcia-Godoy F, Flaitz C. Biological factors in dental caries: Role of saliva and dental plaque in the dynamic process of demineralization and remineralization (part 1). J Clin Pediat Dentist 2003;28:47-52.

18. Contreras D, Martinez T, de la Rosa E, Hemandez R, de la Garza R. Spa P gene of streptococcus mutans in dental plaque and its relationship with early childhood caries. Eur J Pediatr Dent 2011;12:220-224.

19. Loveren V, Buijs JF, Ten Cate JM. Similarity of Bacteriocin Activity Profiles of Mutans streptococci within the Family When the Children Acquire the Strains After the age of 5 . Caries Res 2000;34:481-485.

20. Ten Cate JM ,Mundorff- Shrestha SA. Working group report 1: laboratory models for caries(in vitro and animal models). Adv Dent Res 1995;9:332-334.

21. Dodds M,Edgar W. The relationship between plaque $\mathrm{pH}$, plaque acid anion profiles and oral carbohydrate retention after ingestion of several reference foods by human subjects. J Dent Res 1988;67:861-865.

22. Lee SH, Choi BK, Kim YJ. The cariogenic characters of xylitol-resistant and xylitol-sensitive streptococcus mutans in biofilm formation with salivary bacteria. Arch Oral Biol 2012;57:697-703.

23. Bryans J. Dairy products and dental health. Dental Digest 2006;7:1-4.

24. Bowen WH, Pearson SK. Effect of milk on cariogenesis. Caries Res 1993;27:461-466.

25. Bowen WH, Pearson SK, Rosalen PL, Miguel JC, Shih AY. Assessing the cariogenic potential of some infant formulas, milk and sugar solutions. J Am Dent Assoc 1997;128:865-871.

26. Bowen WH, Lawrence RA. Comparison of the cariogenicity of cola, honey, cow milk, human milk and sucrose. Pediatrics 2005;116:921-926.

27. Chaudhary SD, Chaudhary M, Singh A, Kunte S. An assessment of the cariogenicity of commonly used infant milk formulae using microbiological and biochemical methods. Int J Dent 2011;2011:1-9.

28. Peres R,Coppi L,Volpato M, Groppo F, Cury J, Rosalen P. Cariogenic potential of cows', human and infant formula 
milks and effect of fluoride supplementation. Brit J Nutr 2009;101:376-382.

29. Navia JM, Lopez H. Rat caries assay of reference foods and sugar-containing snacks. J Dent Res 1983;62:893-898.

30. Schuster GS, Navia JM, Amsbaugh S, Larson RH. Source of variability in rat caries studies: microbial infection and caging procedure. J Dent Res 1977;57:355-360.

31. Harper DS, Osborn JC, Clayton R, Hefferren JJ. Modification of food cariogenicity in rats by mineral-rich concentrates from milk. J Dent Res 1987;66:42-45.

32. Larson RH. Merits and modifications of scoring rat dental caries by Keyes' method. In: Symposium and Workshop on Animal Models in Cariology. Sturbridge, Washington 1980. Washington: Information Retrieval, 1981. p. 195-203.

33. Murphy MM, Douglass JS, Johnson RK, Spence LA. Drinking flavored or plain milk is positively associated with nutrient intake and is not associated with adverse effects on weight status in US children and adolescents. J Am Diet Assoc 2008;108:631-639.

34. Gautam SH, Verhagen JV. Evidence that the sweetness of odors depends on experience in rats. Chem Senses 2010; 35:767-776.

35. Martínez MAG, López-Espinoza A, Reséndiz DF, Valdés ME. Sweetened solution intake in albino rats: taste versus calories. Psicothema 2009;21:191-198.

36. Bowen WH, Madison KM, Pearson SK. Influence of desalivation in rats on incidence of caries in intact cage mates. J Dent Res 1988;67:1316-1318.

37. Edgar WM, Bibby BG, Mundorff S, Rowley J. Acid production in plaques after eating snacks: modifying factors in foods. J Am Den Assoc 1975;90:418-425.
38. Miller GD, Jarvis J K, McBean LD. Dairy Foods and Oral Health. In Handbook of Dairy Foods and Nutrition. Third Edition, Boca Raton, FL: CRC Press, Taylor \& Francis. 2006. p. $245-265$.

39. Nunn J. Nutrition and dietary challenges in oral health. Nutrition 2001;17:426-427.

40. Reynolds EC, Black CL. Reduction of chocolate's cariogenicity by supplementation with sodium caseinate. Caries Res 1987;21:44-51.

41. Ito k, Nakamura Y, Tokunaga T, Iijima D, Fukushima K. Anticariogenic properties of a water soluble extract from cacao. Biosci Biotechnol Biochem 2003;67:2567-2573.

42. Ooshima T, Osaka Y, Sasaki H, Osawa K, Yasuda H, Matsumoto M. Cariostatic activity of cacao mass extract. Arch Oral Biol 2000;45:805-808.

43. Paolino VJ, Kashket S. Inhibition of cocoa extracts of biosynthesis of extracellular polysaccharides by human oral bacteria. Arch Oral Biol 1985;30:359-363.

44. Dunning JM, Hodge AT. Influence of cocoa in milk on dental caries incidence. J Dent Res 1971;50:854-859.

45. Johnson RK, Lawrence JA, Brands AM, et al. Dietary Sugars Intake and Cardiovascular Health: A Scientific Statement from the American Heart Association. Circulation 2009; 120:1011-1020.

46. American Academy of Pediatric Dentistry. AAPD Fast Facts. Diet and Dental Health. 2013. Available at: http://www. aapd.org/assets/1/7/FastFacts.pdf.Accessed in March 14, 2014.

47. American Dietetic Association. ADA Reports. Position of the American Dietetic Association: Oral Health and Nutrition. J Am Diet Assoc 2007;107:1418-1428. 